\title{
ANATOMIA DAS RAÍZES DE BACOPA SALZMANII \\ (BENTH.) WETTST. EX EDWALL E BACOPA MONNIERIOIDES (CHAM.) ROBINSON (SCROPHULARIACEAE) EM AMBIENTES AQUÁTICO E TERRESTRE
}

\author{
Cleusa Bona ${ }^{1}$ \\ Berta Lange de Morretes $^{2}$
}

Recebido em 15/01/2002. Aceito em 04/06/2002

\begin{abstract}
RESUMO - (Anatomia das raízes de Bacopa salzmanii (Benth.) Wettst. ex Edwall e B.monnierioides (Cham.) Robinson (Scrophulariaceae) em ambientes aquático e terrestre). O presente trabalho enfoca a anatomia das raízes de Bacopa salzmanii (Benth.) Wettst. Ex Edwall e B. monnierioides (Cham.) Robinson e suas adaptações aos ambientes aquático e terrestre. Foram analisadas raízes adventícias das duas espécies, coletadas no Município de Bonito e no Pantanal do Mato Grosso do Sul. As análises foram feitas do ápice à base da raiz, enfatizando a origem e desenvolvimento dos tecidos. O meristema apical apresenta a mesma estrutura nas duas espécies e não sofre alterações marcantes com a mudança do ambiente. Todos os tecidos se originam de três camadas distintas, na região do promeristema. A endoderme jovem é meristemática e dá origem ao córtex. $\mathrm{O}$ aerênquima é abundante e os septos podem conter espessamento em fi. A exoderme é unisseriada e composta por células curtas e longas. A coifa das duas espécies é pouco desenvolvida e apresenta estrutura semelhante nos dois ambientes.
\end{abstract}

Palavras-chave-Bacopa sp., anatomia da raiz, aerênquima, planta aquática

\begin{abstract}
Anatomy of roots of Bacopa salzmanii (Benth.) Wettst. Ex Edwall and B. monnierioides (Cham.) Robinson (Scrophulariaceae) in aquatic and terrestrial environments). This work describes the anatomy of roots of Bacopa salzmanii (Benth.) Wettst. Ex Edwall and B. monnierioides (Cham.) Robinson and its adaptations to aquatic and terrestrial environments. Both species were collected in the city of Bonito and in the Pantanal (State of Mato Grosso do Sul). Adventitious roots were analyzed, from the apex to the base of the root. Tissues origin and development were emphasized. The apical meristem presents the same structure in both species and it is not significantly altered by the environmental changes. All the tissues are originated from three different layers, in the region of the promeristem. The young endodermis is meristematic and originates the cortex. The aerenchyma is abundant and the septa may contain phi thickenings. The exodermis is uniserial and composed of short and elongated cells. Root cap of both species is few developed in both environments.
\end{abstract}

Key word - Bacopa sp., root anatomy, aerenchyma, aquatic plant

1 Departamento de Botânica, Universidade Federal do Paraná C. Postal 19031, CEP 81531-990, Curitiba, PR, Brasil (clbona@bio.ufpr.br)

2 Departamento de Botânica, Instituto do Biociências da USP. 


\section{Introdução}

As Scrophulariaceae possuem muitos representantes aquáticos importantes. Dentre eles, Bacopa é um gênero que apresenta muitas espécies tropicais, das quais numerosas são aquáticas (Hutchinson 1975). Bacopa salzmanni e $B$. monnierioides caracterizamse pelo hábito anfíbio, conforme citação de Pott \& Pott (1997), ou seja, são espécies que possuem capacidade de sobreviver em solo não alagado, completamente alagado ou mesmo totalmente submersas. Tanto Bacopa monnierioides como B. salzmanii ocorrem, de modo geral, na região Pantaneira, ou em outras áreas alagáveis e margens de rios.

O alagamento periódico do Pantanal levou à instalação de espécies com plasticidade às variações periódicas da lâmina d'água. Bacopa monnierioides e $B$. salzmanii são espécies que se encontram muito bem adaptadas aos períodos de seca e cheia do Pantanal, ou em rios, como B. salzmanii.

É um desafio para fisiologistas e ecologistas entender por que espécies de ambientes alagados podem prosperar sob condições de excesso de água, enquanto que espécies de ambientes não alagados não podem. A maior dificuldade para as plantas sujeitas à submersão é suportar a deficiência de oxigênio na água e no solo submerso e as fitotoxinas liberadas pelos micróbios anaeróbicos. Além disso, a ausência de oxigênio nas partes internas da raiz mata as células meristemáticas (Armstrong et al. 1991).

Plantas herbáceas que sobrevivem em ambientes com pouco oxigênio estão geralmente associadas com a formação de raízes adventícias superficiais e também com o desenvolvimento de aerênquima (Drew 1987; Armstrong et al. 1991). As raízes desenvolvidas em solos permanentemente alagados apresentam menor crescimento e peso seco (Armstrong et al. 1991). Essas raízes normalmente são mais curtas e de maior diâmetro (Williams \& Barber 1961).

$\mathrm{O}$ interesse em conhecer a anatomia de espécies anfíbias surgiu do fato de elas, muitas vezes, sofrerem grandes variações morfológicas e estruturais entre os indivíduos de solo inundado e não inundado, dificultando muitas vezes sua identificação. A facilidade com que essas espécies se adaptam em meios tão distintos e as estratégias por elas utilizadas são de fato curiosas e pouco exploradas para as espécies brasileiras.

Os estudos anatômicos com espécies de Scrophulariaceae estão concentrados nas plantas de interesse comercial, sendo na maioria relativos aos órgãos reprodutivos (Varghese 1970; 1971; Harkiss 1971; 1972; Armstrong \& Douglas 1989; Ponzi \& Pizzolongo 1992). Poucos são os trabalhos desenvolvidos com os órgãos vegetativos (Borgesen \& Arechong e Durval ambos apud Solereder 1908; Prasad 1947; Carlomagno 1949; Charlton 1966; Renaudin \& Capdepon 1979; Michener 1981; Turgeon et al. 1993). O conhecimento anatômico de $B$. salzmanii e $B$. monnierioides crescendo em diferentes ambientes acrescentará dados inéditos à família.

O comportamento dessas espécies diante das variações hídricas que ocorrem no Pantanal, a escassez de trabalhos sobre a flora dessa região e o desconhecimento da estrutura anatômica levou-nos a desenvolver este trabalho. O objetivo principal deste é registrar as variações morfológicas e anatômicas sofridas por essas espécies nos diferentes ambientes; caracterizar a estrutura anatômica da raiz através da ontogênese, bem como fornecer dados para futuros trabalhos referentes a outras áreas de pesquisa.

\section{Material e métodos}

O material botânico de Bacopa monnierioides foi coletado durante os anos 1994 a 1996 e de Bacopa salzmanii em 1996 e 1997. Bacopa salzmanii foi coletada na nascente do rio Sucuri (planta aquática) e nas margens deste mesmo rio (planta terrestre), na Fazenda São 
Geraldo, Município de Bonito, MS, entre as coordenadas $21^{\circ} 15^{\prime} 52^{\prime \prime}$ S e $56^{\circ} 33^{\prime} 33^{\prime \prime}$ W. As plantas aquáticas dessa espécie encontravam-se completamente submersas e as plantas terrestres, em solo úmido. Bacopa monnierioides foi coletada no Pantanal do Abobral, às margens da Estrada Parque, Município de Corumbá - MS (planta aquática), e na fazenda São Bento, Município de Miranda, MS, entre as coordenadas $19^{\circ} 28^{\prime} 32^{\prime \prime} \mathrm{S}$ e $57^{\circ} 02^{\prime} 39^{\prime \prime} \mathrm{W}$ (planta terrestre). As plantas aquáticas de B. monnierioides encontravam-se fixas ao substrato e com ramos emergentes, enquanto as plantas terrestres cresciam em solo arenoso e úmido.

As exsicatas encontram-se depositadas no herbário UPCB da UFPR em Curitiba e no herbário SPF da USP, sob os números: Bona, C. 116 (B. monnierioides) e Scremin, D.E et al., 277, 278 (B. salzmanii).

As planícies e pantanais mato-grossenses ocupam cerca de $133.465 \mathrm{~km}^{2}$ da bacia do alto Paraguai (IBGE 1989). Situam-se nos Estados de Mato Grosso e Mato Grosso do Sul, entre as coordenadas de $16^{\circ}$ e $22^{\circ} \mathrm{S}$ e $55^{\circ}$ e $58^{\circ} \mathrm{W}$. O verão é úmido, com temperatura média de $32^{\circ} \mathrm{C}$ a $33^{\circ} \mathrm{C}$, e o inverno é seco, com geadas ocasionais e temperatura média de $21^{\circ} \mathrm{C}$ a $29^{\circ} \mathrm{C}$. A precipitação pluviométrica anual é concentrada no período de novembro a abril, com níveis de 1.100 a 1.300 milímetros (CadavidGarcia 1984). Os solos são sedimentares, hidromórficos, geralmente arenosos e de baixa fertilidade (Amaral 1982).

O município de Bonito, MS compreende área de 4.947,90 km², entre as coordenadas $21^{\circ}$ 07 ' $16^{\prime \prime} \mathrm{S}$ e $56^{\circ} 28^{\prime} 55^{\prime \prime}$ W (SEPLAN Secretaria de Estado e Finanças, Orçamento e Planejamento do Mato Grosso do Sul). A região é predominantemente calcária e os rios caracterizam-se pela água extremamente límpida. O relevo é parcialmente cárstico, com morros isolados e serras alongadas constituídas de rochas carbonáticas.

Os estudos morfo-anatômicos envolveram raízes adventícias das plantas desenvolvidas em ambiente aquático e terrestre. A fixação foi feita com FAA 50 ou 70 (Johansen 1940). As raízes foram analisadas em diferentes níveis ao longo de toda sua extensão, por meio de secções transversais e longitudinais.

As peças destinadas à confecção de lâminas permanentes foram emblocadas em historresina (JB4-GMA-glicol metacrilato) segundo a técnica de Feder \& O'Brian (1968). Os blocos foram seccionados em micrótomo rotatório com cerca de $5 \mu \mathrm{m}$ de espessura. As secções foram coradas com azul de toluidina (O’Brian et al. 1964) ou com fucsina básica e azul de astra (Alves de Brito \& Alquini 1996), e as lâminas, montadas com resina sintética (Entelan). Para detectar amido foi feito teste histoquímico com lugol (Roth 1964).

Para estimar o diâmetro das raízes e a percentagem de área lacunar, foram feitas 20 mensurações em dez plantas de cada ambiente. As mensurações foram feitas em raízes bem desenvolvidas, a $1 \mathrm{~cm}$ de distância do caule. As secções transversais foram desenhadas esquematicamente, com auxílio da câmara clara, e posteriormente medidas com auxílio da mesa digitalizadora. Com os dados de área total e área lacunar calculou-se a percentagem da área lacunar.

Para obtenção das medidas dos elementos de vaso, o material foi dissociado em solução de Franklin (Franklin 1946). As lâminas foram montadas de forma semipermanente com gelatina glicerinada. Foram feitas 50 mensurações do comprimento e diâmetro dos elementos de vaso das raízes das plantas provenientes de cada um dos ambientes.

As fotomicrografias foram realizadas em microscópio Axiolab da marca Zeiss.

\section{Resultados}

Tanto as plantas aquáticas quanto as terrestres de $B$. salzmanii desenvolvem raízes adventícias ao longo do caule. As raízes 
aquáticas mostram aumento de diâmetro significativo em relação às raízes terrestres (Tab. 1), e muitas vezes são clorofiladas.

Bacopa monnierioides tem amplo crescimento vegetativo e desenvolve muitas raízes adventícias ao longo do caule. Essas raízes são curtas, finas e tortuosas nas plantas terrestres; longas, cilíndricas, retas e de diâmetro significativamente maior nas plantas aquáticas (Tab. 1).

Tabela 1. Médias do diâmetro ( $\mathrm{mm}$ ) das raízes adventícias de Bacopa salzmanii e Bacopa monnierioides. Média (M); desvio padrão (DP).

\begin{tabular}{lcclll}
\hline \multirow{2}{*}{ Ambiente } & \multicolumn{2}{c}{ B. salzmanii } & & \multicolumn{2}{c}{ B. monnierioides } \\
\cline { 2 - 3 } & $\mathrm{M}$ & $\mathrm{DP}$ & & $\mathrm{M}$ & $\mathrm{DP}$ \\
\hline aquático & $\mathbf{0 , 7 9 *}$ & 0,07 & & $\mathbf{1 , 6 *}$ & 0,17 \\
terrestre & $\mathbf{0 , 6 6 *}$ & 0,11 & & $\mathbf{0 , 9 7 *}$ & 0,17 \\
\hline
\end{tabular}

Médias seguidas de asterisco, na coluna, diferem estatisticamente pelo teste $t(p<0,05)$. $n=20$

O ápice das raízes de $B$. salzmanii B. monnierioides, em secção longitudinal, mostra na região meristemática três áreas distintas: uma camada externa (dermatogênio) que origina a epiderme por meio de divisões anticlinais e a coifa, através de divisões periclinais; uma camada mediana (periblema) que forma os tecidos corticais; um grupo interno de células (pleroma), que origina o cilindro vascular (Fig. 1, 12). A coifa é pouco desenvolvida e possui estatolitos (amiloplastos). A estrutura apical da raiz é semelhante nos dois ambientes.

Secções transversais do ápice da raiz, ainda protegido pela coifa, revelam de fora para dentro os seguintes estratos: duas camadas de células com paredes delgadas e citoplasma hialino, fazendo parte da coifa; três estratos de células com paredes delgadas, citoplasma denso e núcleos grandes, sendo a externa a epiderme, a média a exoderme, e a interna pertencente ao parênquima cortical (Fig. 2, 11). Nesse estádio de desenvolvimento, o parênquima cortical é composto por células dispostas em fileiras radiais que delimitam entre si pequenos espaços quadrangulares e sua camada interna (endoderme) é meristemática e sofre divisões sucessivas, formando a maior parte do córtex. Isso fica claro devido à coloração escura do protoplasto das células mais internas, indicando que são mais jovens. Neste estádio de desenvolvimento, o cilindro central já possui o periciclo nítido, porém os elementos vasculares ainda estão indiferenciados (Fig. 2, 11).

À medida que a raiz se desenvolve, as fileiras de células do parênquima cortical separam-se radialmente, formando câmaras de grandes proporções (Fig. 3, 5, 13).

Os primeiros elementos vasculares começam a se diferenciar na posição onde termina a coifa (Fig. 3, 14). Neste nível, muitos pêlos radiciais encontram-se em desenvolvimento.

As raízes dessas espécies, em estrutura primária, apresentam células epidérmicas estreitas e longas, com paredes delgadas, não tendo sido detectada, em microscopia fotônica, a presença de cutícula. Essas células são menores que as da exoderme, e à medida que aumenta o diâmetro da raiz, sofrem deformações ou rompimento quando a raiz atinge a estrutura secundária. Nesse caso, a exoderme passa a ser o tecido protetor externo. Como nas raízes das plantas aquáticas o crescimento secundário é incipiente, a epiderme persiste, ficando em muitos locais apenas colabada (Fig. 5, 8, 23).

Pêlos radiciais foram observados em pequena quantidade em $B$. monnierioides e em grande quantidade em $B$. salzmanii, nas plantas aquáticas e terrestres. Esses pêlos surgem a partir de qualquer célula epidérmica. Essas células mostram citoplasma denso quando jovens (Fig. 4).

Internamente à epiderme ocorre exoderme uniestratificada, que possui células curtas e longas. As células longas possuem paredes delgadas revestidas internamente por uma lamela de suberina. As células curtas 

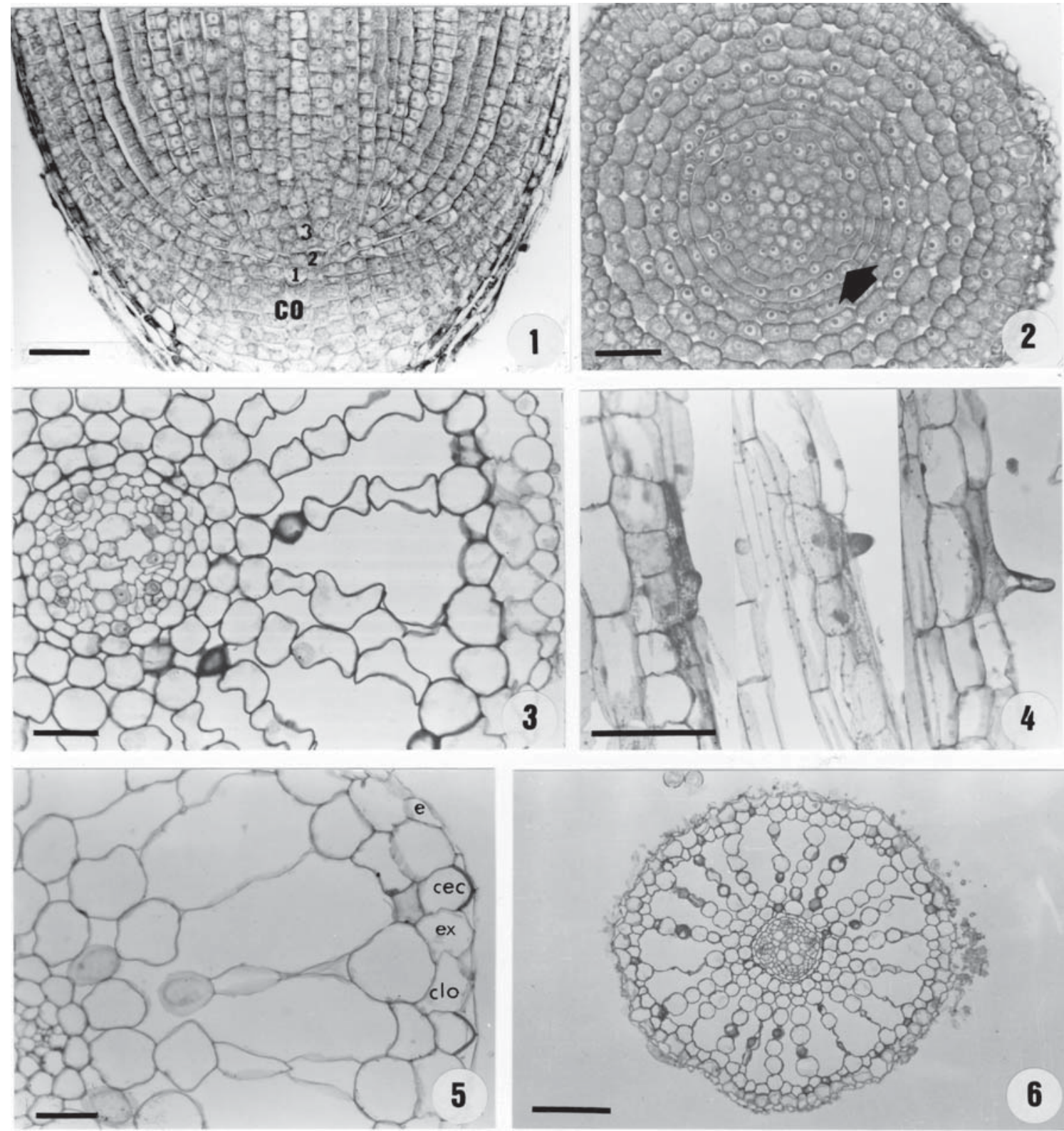

Figuras 1 a 6. Raiz adventícia de Bacopa salzmanii; 1. Secção longitudinal da raiz aquática, na região do meristema subapical - (co) columela, (1) dermatogênio, (2) periblema, (3) pleroma, (barra $=40 \mu \mathrm{m}) ; 2$. Secção transversal do ápice da raiz aquática, na região do meristema subapical, (cabeça de seta) endoderme, (barra $=40 \mu \mathrm{m}$ ); 3. Secção transversal de uma raiz aquática, na região da zona pilífera $($ barra $=40 \mu \mathrm{m}) ; 4$. Secções longitudinais da raiz aquática, evidenciando três fases de desenvolvimento dos pêlos radiciais $($ barra $=10 \mu \mathrm{m})$; 5. Secção transversal de uma raiz terrestre, (e) epiderme, (ex) exoderme, $(\mathrm{cec})$ célula curta, $(\mathrm{clo})$ célula longa, $($ barra $=40 \mu \mathrm{m}) ; 6$. Secção transversal de uma raiz aquática na região da zona pelífera $($ barra $=200 \mu \mathrm{m})$. 

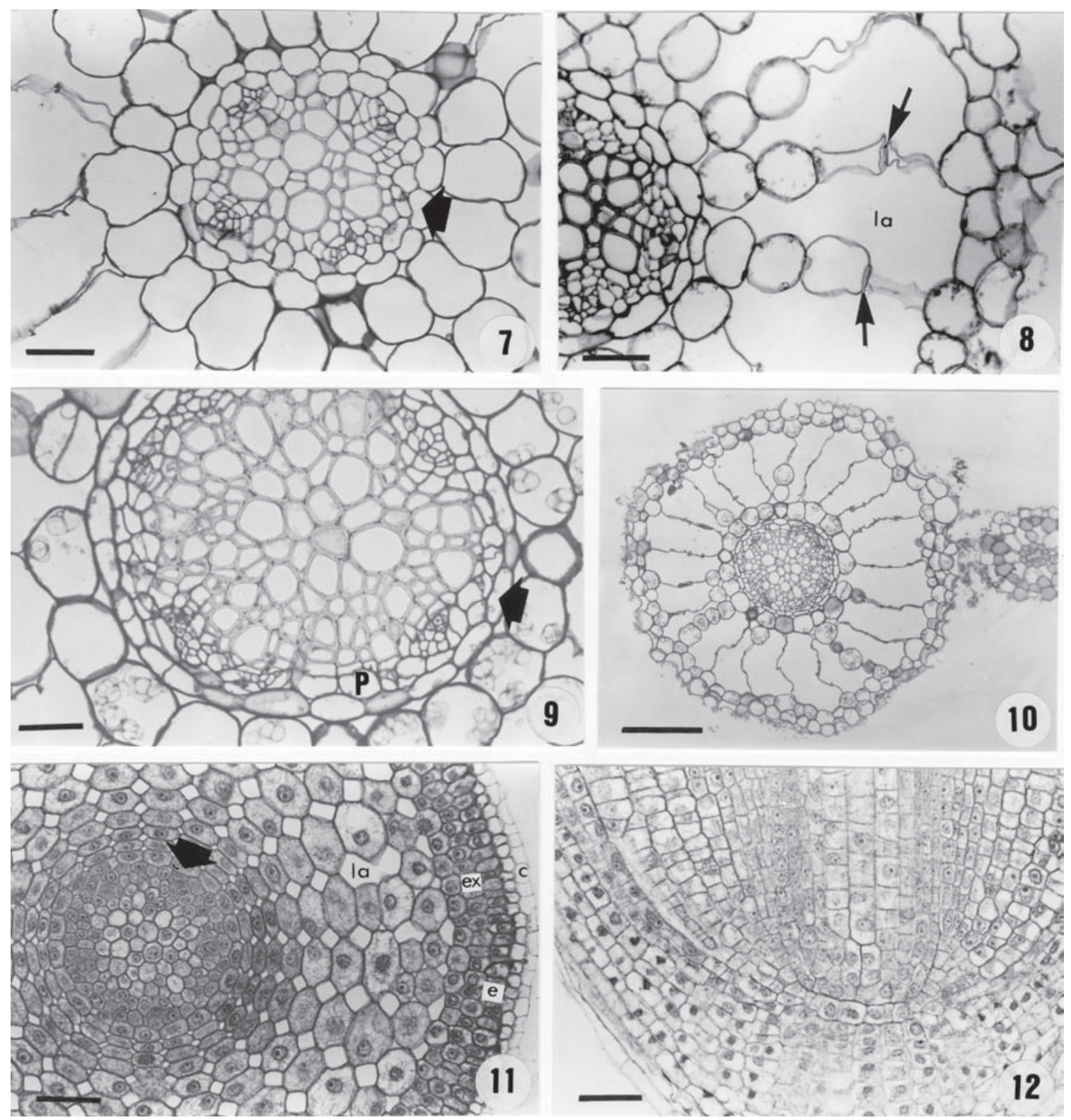

Figuras 7 a 10. Raiz de Bacopa salzmanii; Figuras 11 e 12. Raiz de Bacopa monnierioides; 7. Secção transversal de uma raiz aquática, (cabeça de seta) endoderme, (barra $=40 \mu \mathrm{m}$ ); 8 . Secção transversal de uma raiz aquática, (setas) espessamento em fi, (la) lacuna, (barra $=40 \mu \mathrm{m})$; 9 e 10 Secções transversais de raízes terrestres, (cabeça de seta) endoderme, $(\mathrm{p})$ periciclo, (9. barra $=40 \mu \mathrm{m}, 10$. Barra $=200 \mu \mathrm{m}) ; 11$. Secção transversal do ápice da raiz aquática, (c) coifa, (e) epiderme, (ex) exoderme, (la) lacuna, (cabeça de seta) endoderme, (barra $=40 \mu \mathrm{m}) ; 12$. Secção longitudinal do meristema subapical de uma raiz aquática $($ barra $=40 \mu \mathrm{m})$. 

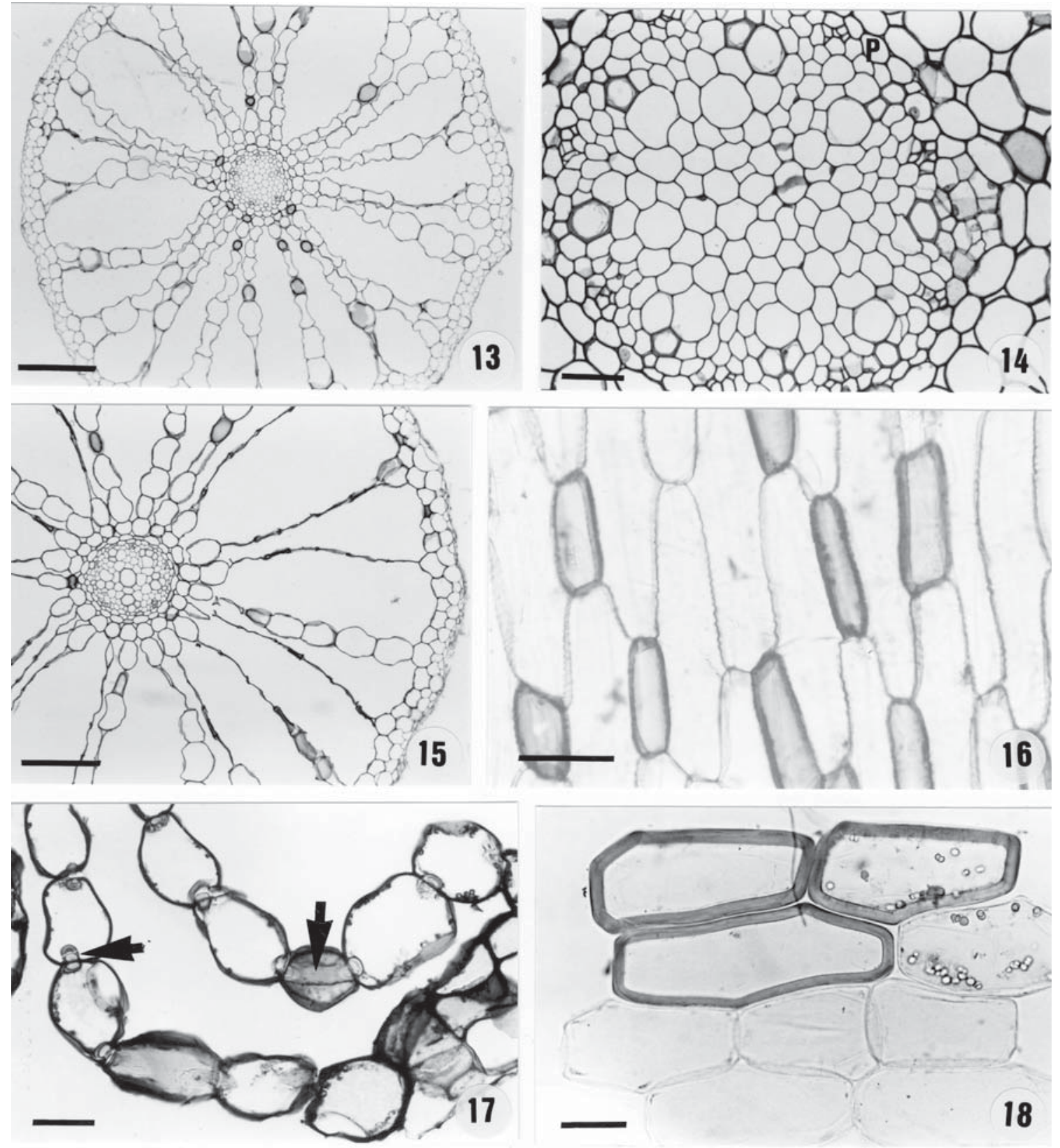

Figuras 13 a 18. Raiz de Bacopa monnierioides; 13, 14 e 15 Secções transversais de raízes aquáticas, (p) periciclo, (13 e 15. barra $=200 \mu \mathrm{m}, 14$. barra $=40 \mu \mathrm{m}) ; 16$. Exoderme em vista frontal (barra $=50 \mu \mathrm{m}) ; 17$. Septos, em secção transversal, (setas) espessamento em fi, $($ barra $=50 \mu \mathrm{m})$; 18. Septo com espessamento em fi, em vista frontal $($ barra $=40 \mu \mathrm{m})$. 

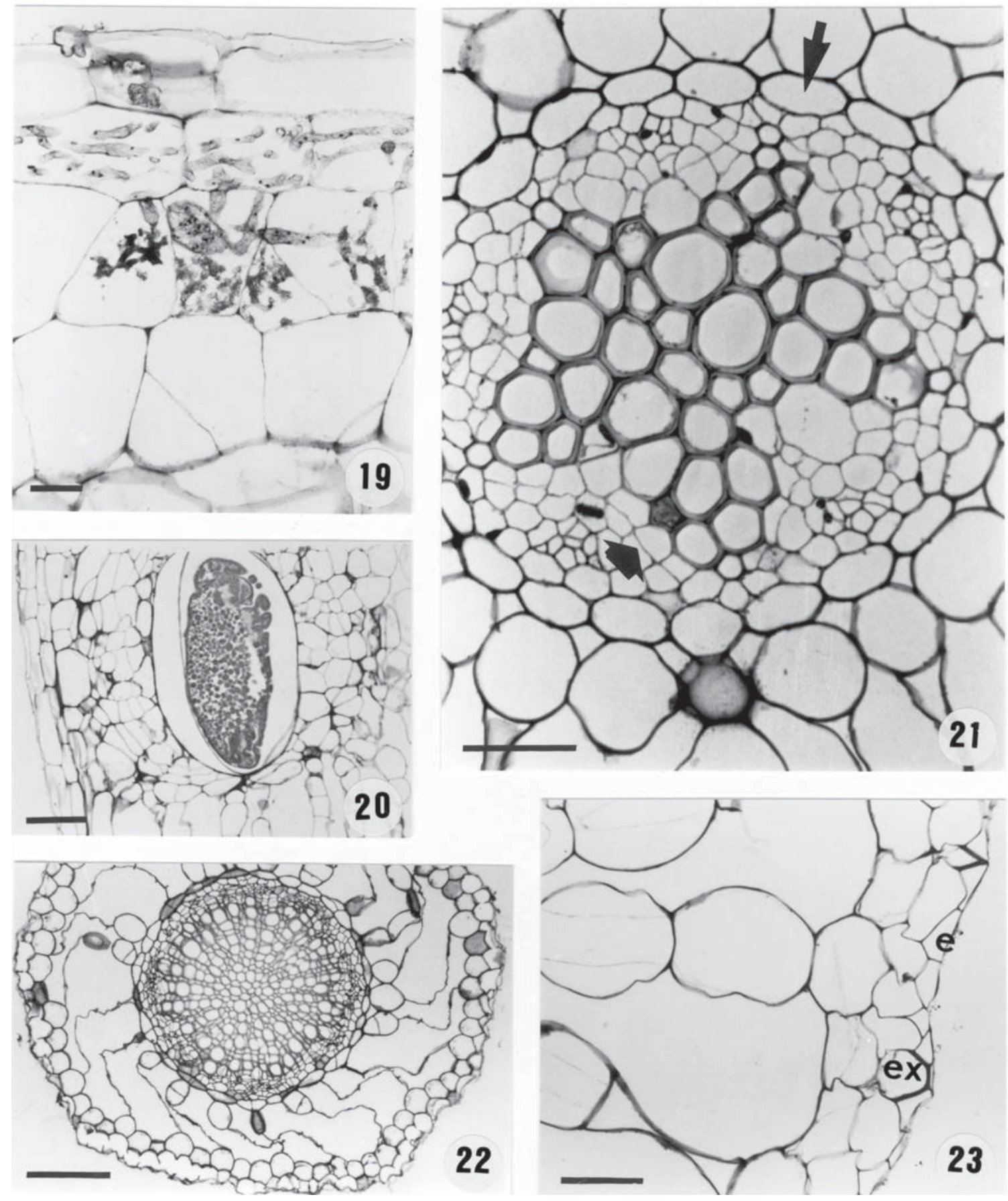

Figuras 19 a 23. Raiz de Bacopa monnierioides; 19. Células corticais com micorriza (barra $=50 \mu \mathrm{m}$ ); 20. Galha no córtex de uma raiz aquática (barra $=200 \mu \mathrm{m}$ ); 21 . Secção transversal de uma raiz terrestre evidenciando a instalação do câmbio, (seta) endoderme, (cabeça de seta) câmbio; 22. Secção transversal de uma raiz terrestre com estrutura secundária (barra $=200 \mu \mathrm{m}) ; 23$. Secção transversal de uma raiz aquática, $(\mathrm{ex})$ exoderme, (e) epiderme, $($ barra $=50 \mu \mathrm{m})$. 
apresentam paredes periclinais externas e parte das anticlinais espessadas e lignificadas. As células curtas distribuem-se aleatoriamente entre as células longas (Fig. 5, 16, 23). As paredes anticlinais das células longas apresentam delicadas sinuosidades no material das lâminas semipermanentes (Fig. 16). A exoderme possui as mesmas características nas plantas aquáticas e terrestres.

A maior parte do córtex é constituída de aerênquima, com lacunas grandes dispostas radialmente. As raízes das plantas aquáticas de B. monnierioides possuem, em média, 57\% de área lacunar, e as raízes das plantas terrestres, cerca de 47\%. Em B. salzmanii, apesar de o diâmetro das raízes das plantas aquáticas ser maior, a percentagem de área lacunar não varia entre as plantas dos dois ambientes. As raízes das plantas aquáticas possuem, em média, 38\% de área lacunar, e as das plantas terrestres, cerca de 39\%. As lacunas são separadas entre si por septos unisseriados (Fig. 6, 10, 13, 15, 22).

Os septos, em vista frontal, revelam células quadradas a retangulares, que podem ou não deixar espaços entre si (Fig. 18). Nas regiões mais velhas das raízes terrestres, algumas células dos septos desenvolvem, ao longo das paredes anticlinais-transversais e periclinais, anéis de natureza secundária, os chamados espessamentos em fi (Ø) (Fig. 8, 17, 18). As células dos septos colapsam à medida em que a raiz envelhece, restando apenas as paredes colabadas (Fig. 5, 6, 10, 15, 22). Em algumas raízes de $B$. monnierioides todos os septos ficam colabados.

A endoderme é uniestratificada e apresenta típicas estrias de Caspary. As células endodérmicas são mais achatadas e dividem-se anticlinalmente nas raízes com crescimento secundário (Fig. 7, 9, 14, 21, 22).

Micorrizas ocorrem com grande freqüência na região cortical das raízes aquáticas (Fig. 19), e galhas também podem estar presentes (Fig. 20).

Amiloplastos com grãos de amido simples ou compostos são comuns nas raízes das plantas terrestres, porém ausentes ou muito reduzidos nas plantas aquáticas de $B$. monnierioides e estão em maior quantidade nas plantas aquáticas de B. salzmanii (Fig. 9). Nas regiões mais velhas das raízes, onde os septos estão colabados, o amido localiza-se nas células periféricas do córtex, as quais se mantêm íntegras. $\mathrm{O}$ amido presente na endoderme geralmente é formado por grãos menores que os da região cortical (Fig. 9).

A camada externa do cilindro vascular é representada por um periciclo unisseriado (Fig. $9,14,21,22)$, o qual se torna pouco nítido nas raízes em estrutura secundária (Fig. 22). O sistema vascular pode apresentar número variado de pólos xilemáticos, comumente de cinco a oito em $B$. monnierioides, e três a cinco em B. salzmanii, porém esse número é constante na mesma raiz, não importando a altura em que foi feita a secção (Fig. 7, 9, 14, 21). Na extremidade da raiz a região central ainda não é ocupada pelo metaxilema (Fig. 14). Os elementos do xilema diferenciam-se gradativamente, ocupando toda a região central do cilindro vascular (Fig. 7, 21). Nesse estádio de desenvolvimento instalam-se os arcos cambiais (Fig. 21). A estrutura primária mantém-se na maioria das raízes aquáticas de ambas as espécies. Crescimento secundário ocorre nas regiões mais velhas das raízes terrestres. Nesse caso, apenas o xilema desenvolve-se significativamente (Fig. 10, 22).

Os elementos de vaso do metaxilema e do xilema secundário das plantas aquáticas, bem como das plantas terrestres, são longos e estreitos, havendo diferença significativa apenas no comprimento dessas células para B. monnierioides (Tab. 2). Os elementos em questão são mais longos nas plantas aquáticas do que nas terrestres. As paredes laterais são pontoadas e as placas de perfuração são simples e geralmente terminais, com ligeira inclinação. Algumas vezes podem ocorrer placas de perfuração laterais. 
Tabela 2. Médias do comprimento e diâmetro $(\mu \mathrm{m})$ dos elementos de vaso das raízes adventícias de Bacopa salzmanii e Bacopa monnierioides. Média (M); desvio padrão (DP).

\begin{tabular}{|c|c|c|c|c|c|c|c|c|}
\hline \multirow{3}{*}{ Ambiente } & \multicolumn{4}{|c|}{ B. salzmanii } & \multicolumn{4}{|c|}{ B. monnierioides } \\
\hline & \multicolumn{2}{|c|}{ compr. } & \multicolumn{2}{|c|}{ diâm. } & \multicolumn{2}{|c|}{ compr. } & \multicolumn{2}{|c|}{ diâm. } \\
\hline & M & DP & M & DP & $\mathrm{M}$ & DP & M & $\mathrm{D}$ \\
\hline & 306 & 133 & 23 & 5 & 599* & 174 & 25 & \\
\hline terrestre & 304 & 97 & 25 & 5 & $313^{*}$ & 210 & 25 & \\
\hline
\end{tabular}

Médias seguidas de asterisco, na coluna, diferem estatisticamente pelo teste $\mathrm{t}(\mathrm{p}<0,05) . \mathrm{n}=50$

Com o crescimento secundário o floema sofre pequenas alterações, ficando comprimido entre o xilema e o periciclo, não ocorrendo variação no diâmetro das raízes. Em conseqüência da instalação do xilema secundário ocorre deformação dos septos da região cortical (Fig. 22).

\section{Discussão}

O pequeno aumento no número de raízes da planta aquática de Bacopa salzmanii deve estar relacionado a maior oxigenação da água, pois a espécie em questão habita águas correntes. Pannier (1960) e Sculthorpe (1967) admitem que a água movimentada normalmente é mais oxigenada. O grande comprimento das raízes aquáticas de $B$. monnierioides pode estar relacionado ao fato de a planta estar em ambiente lêntico de águas turvas, e também à capacidade de formar aerênquima. Segundo Armstrong et al. (1991), a formação do aerênquima pode permitir a sobrevivência da raiz em estratos mais profundos.

As espécies estudadas não sofreram as acomodações típicas de plantas terrestres sujeitas ao alagamento, com produção de grande quantidade de raízes curtas e superficiais, mas assemelharam-se àquelas tipicamente aquáticas, pela presença de aerênquima bem desenvolvido.

O tipo de meristema subapical encontrado em B. salzmanii e B. monnierioides é um dos tipos principais das dicotiledôneas citados por Romberger (1963), Esau (1974) e Cutter (1987). Romberger (1963) cita que a organização do meristema da raiz das Scrophulariaceae é do tipo referido acima.

Nas espécies de Bacopa estudadas a coifa não sofre alterações com a mudança do ambiente, enquanto que, em algumas espécies cultivadas na água, a coifa pode não se desenvolver (Richardson 1955), ou ser bem desenvolvida (Sculthorpe 1967).

A presença de aerênquima próximo à zona meristemática nas raízes de $B$. salzmanii e B. monnierioides evidencia a capacidade de adaptação dessas ao ambiente aquático. Segundo Drew (1987) e Gaynard \& Armstrong (1987), raízes de plantas de ambientes não alagados não têm a mesma estrutura para conservar o oxigênio e conduzi-lo até o ápice, permitindo sua sobrevivência.

Quando se fala de pêlos radiciais em plantas aquáticas, a primeira impressão é que estes não estão presentes. As observações realizadas em B. salzmani e em B. monnierioides mostram que cada uma apresenta características próprias. Nessas espécies, a formação de pêlos radiciais, parece não estar relacionada à maior ou menor quantidade de água. Agami \& Waisel (1986) mostram que esse assunto é muito discutido. Enquanto vários autores registraram a ausência desses em algumas espécies (Cormack 1937; Persecke et al. apud Guttenberg 1968; Mauseth 1988; Fahn 1990), outros referem que pêlos radiciais podem ser formados pela maioria das espécies (Pearsall 1918a; 1918b; Arber 1920; D'Almeida 1942; Shannon 1953; Sculthorpe 1967; Guttenberg 1968). No entanto, Søndergaard \& Laegaard (1977) referem que algumas plantas submersas não mostraram o mesmo resultado citado por Dale (1951).

A exoderme de $B$. salzmanii $\mathrm{e}$ B. monnierioides apresenta estrutura semelhante àquela descrita por Guttenberg (1968) para as Scrophulariaceae. Uma lamela contínua de suberina no interior da parede primária 
também foi registrada por vários autores (Guttenberg 1940; 1968; Scott apud Guttenberg 1968; Mauseth 1988; Fahn 1990). A presença de estrias de Caspary na exoderme foi registrada por Van Fleet (1950), Peterson et al. (1982), Perumalla et al. (1990) e Eschrich (1995). Perumalla et al. (1990) sugeriram que, provavelmente, todas as espécies com exoderme suberizada também possuem estrias de Caspary. Todavia, essa estrutura não foi evidenciada nas espécies estudadas. Novas técnicas deverão ser testadas para confirmar a presença ou ausência de estrias de Caspary nesse tecido. A exoderme nessas espécies difere daquelas apresentadas por Guttenberg (1968), por não ter um padrão organizado na distribuição das células curtas, e por essas apresentarem maior variação no seu comprimento. A presença de paredes periclinais externas espessadas, semelhante àquelas de B. salzmanii e B. monnierioides, também foi referida por Guttenberg (1968) para xerófitas e algumas aquáticas.

A sinuosidade nas paredes das células exodérmicas foi registrada por Pristley \& North (1922), Van Fleet (1961), Guttenberg (1968) e Perumalla et al. (1990). Para Pristley \& North (1922) e Van Fleet (1961), geralmente esta é uma característica associada à presença da estria de Caspary. Guttenberg (1968) registra que as células exodérmicas perdem a elasticidade após a deposição da suberina, não podendo acompanhar a contração do órgão, e em função desse fato, se apresentam mais ou menos sinuosas.

Segundo Barnabas (1996), algumas aquáticas de água doce não apresentam exoderme com estrias de Caspary, talvez por não terem necessidade de excluir determinados solutos, como o cloreto de sódio, dos tecidos da raiz. Segundo esse autor, mais estudos são necessários para entender a função de duas faixas com estrias de Caspary na maioria das plantas aquáticas. Segundo Armstrong \& Armstrong (1988), Koncalová (1990) e Armstrong et al. (1991), as plantas tolerantes ao alagamento provavelmente evitam perda radial de $\mathrm{O}_{2}$ para o solo anóxico, podendo a exoderme ter essa função. É possível que a exoderme de $B$. salzmanii e $B$. monnierioides também tenha essa função, no entanto, são necessários novos estudos para confirmação.

Em B. salzmanii e B. monnierioides a exoderme tem papel fundamental, que é o de substituir a epiderme quando essa se desestrutura. Portanto, nessas espécies é fundamental que haja suberização. Guttenberg (1968) afirma que a suberização da exoderme ocorre antes da morte das células epidérmicas. Essa característica foi registrada para as espécies por nós estudadas. Concordamos com Smith et al. (1986) que esse tecido não impede a entrada de fungos no córtex, visto a ocorrência de micorrizas no interior das raízes.

A atividade meristemática da endoderme jovem foi registrada por Williams (1947). O autor enfatiza que o arranjo radial das células corticais e o protoplasto denso das células que circundam o pleroma sugerem a natureza cambial dessa camada, visto que as células mais internas são mais jovens. Em B. salzmanii e B. monnierioides, vê-se claramente que a endoderme e o periciclo têm origem distinta, pela disposição e tamanho de suas células, concordando com as observações de Williams (1947). Nas plantas aquáticas a endoderme mais o aerênquima são essenciais para estocagem e distribuição de oxigênio nos tecidos (Sorrell \& Dromgoole 1988; 1989; Sorrell 1991). Outro possível papel para a endoderme é formar uma barreira para patógenos (Van Fleet 1961).

Um dos caracteres mais marcantes das hidrófitas é a presença de aerênquima. Esse tecido foi bem documentado por Arber (1920), Sifton (1945, 1957), Sculthorpe (1967), Kaul (1976), Justin \& Armstrong (1987) e Laan et al. (1989). Em B. salzmanii e B. monnierioides o sistema lacunar é contínuo através da planta, concordando com as observações feitas por Williams \& Barber (1961) e Sculthorpe (1967). Os autores acreditam que os órgãos enterrados 
recebem oxigênio dos ramos através do sistema lacunar, e concluíram que sem o aerênquima as plantas aquáticas não sobreviveriam à ausência ou baixa concentração e difusão de oxigênio na água e à presença de fitotoxinas. Armstrong et al. (1991) referem que quanto mais profundas as raízes, maiores são os espaços de ar.

A maior percentagem de área lacunar nas raízes de $B$. monnierioides que cresceram em ambiente lêntico poderia ser justificada pela concentração de oxigênio na água. De acordo com Pannier (1960) e Sculthorpe (1967) em ambientes aquáticos bem oxigenados, como rios de água corrente e cachoeiras, as plantas podem não desenvolver sistema lacunar, enquanto que em águas com pouco oxigênio as lacunas podem ser bem desenvolvidas. No entanto, para confirmar essa hipótese para as espécies avaliadas seria necessário quantificar o teor de oxigênio na água.

O padrão do aerênquima (radiado) presente na raiz de $B$. salzmanii e $B$. monnierioides assemelha-se ao descrito por Smits et al. (1990). Segundo Barratt (1916), Hulbary (1944), Dale (1957), Justin \& Armstrong (1987), Armstrong et al. (1994) e Bona \& Morretes (1997), a origem, a estrutura do aerênquima e a percentagem de área lacunar são bastante variáveis entre os diferentes táxons. Aerênquima de origem esquizógena, como observado nas espécies de Bacopa estudadas, é mais comum em órgãos aéreos (Sculthorpe 1967). Segundo esse autor, os órgãos que crescem em ambientes desprovidos de luz, geralmente, possuem lacunas lisígenas. No caso de $B$. salzmanii e $B$. monnierioides ocorre colapso celular nos septos, o que provavelmente é uma estratégia para reduzir o consumo de oxigênio. Essa característica parece ser exclusiva das raízes com aerênquima esquizógeno e também foi observada por Klinge (apud Guttenberg 1968), John (1977) e Justin \& Armstrong (1987). O padrão de colapso celular confere com o tipo gramináceo referido por Justin \& Armstrong (1987). Nas espécies estudadas, os septos colabam de forma aleatória, diferentemente da observação de Konings \& Verschuren (1980), onde os septos se mantêm íntegros na direção oposta aos pólos de protoxilema. Em $B$. salzmanii e $B$. monnierioides há colapso celular nos septos que envolvem as raízes laterais, diferindo das observações de Smirnoff \& Crawford (1983) e Justin \& Armstrong (1987).

A maior proporção de área lacunar nas raízes de $B$. monnierioides pode estar relacionada ao ambiente em que a planta cresceu, que provavelmente possui água com menor teor de oxigênio. Segundo Sculthorpe (1967), a proporção de lacunas varia de acordo com a espécie, tamanho e idade do órgão. Essa variação foi registrada por Conway (1937), Coult (1964), Smits et al. (1990) e Blom (1990). Algumas espécies tolerantes ao alagamento aumentam várias vezes a área lacunar quando submergidas, enquanto que outras, com porosidade abaixo de $10 \%$, conseguem sobreviver em ambiente alagado por meio de enraizamento superficial (Laan et al. 1989; Justin \& Armstrong 1987).

O arranjo cúbico das células corticais da raiz de $B$. salzmanii e $B$. monnierioides e a formação de alta percentagem de área lacunar conferem a essas espécies melhor adaptação ao ambiente aquático. Justin \& Armstrong (1987) encontraram ligação entre a configuração das células corticais e o ambiente de solo alagado. Segundo os autores, o padrão hexagonal está mais associado a plantas que não toleram alagamento, enquanto que o arranjo cúbico é o mais comum em espécies alagadas e intermediárias. Armstrong et al. (1994) encontraram maior porosidade em plantas com padrão de tecido com células cúbicas.

A variação no número de pólos de protoxilema encontrada nas raízes de B. salzmanii e B. monnierioides parece ser o comum nas Scrophulariaceae: Linaria vulgaris, por exemplo, apresenta raízes diarcas a hexarcas (Charlton 1966). 
Nas plantas aquáticas de B. salzmanii e B. monnierioides o floema não sofre alterações e não há modificações drásticas do xilema, apenas redução na lignificação e na quantidade de tecidos secundários, concordando com as observações de Cheadle \& Whitford (1941), Hasman \& Inanç (1957) e Sculthorpe (1967). Quanto ao sistema vascular das raízes, Sculthorpe (1967) refere que as Magnoliopsida e Liliopsida aquáticas exibem vários graus de redução.

A reserva de amido foi significativamente maior na planta submersa de B. salzmanii, concordando com as observações feitas por Fahn (1990), Hostrup \& Wiegleb (1991) e Rascio et al. (1994). Segundo Brändle \& Crawford (1987), o acúmulo de amido é uma adaptação metabólica para hipoxia, que garante adequada reserva de carbono para caso de aumento da demanda. De acordo com os autores, já se demonstrou em muitos estudos que um adequado suprimento de carboidratos pode ser crítico para a sobrevivência dos tecidos com baixa concentração de $\mathrm{O}_{2}$. Steinmann \& Bräendle (1984) mostraram que plantas com rizoma são as que possuem a maior capacidade para sobreviver em ambientes anaeróbicos, devido à grande reserva de carboidratos e essas reservas mostram consideráveis variações durante $o$ ano.

Como as espécies de Bacopa não são rizomatosas, o amido fica acumulado principalmente nos cloroplastos da folha e caule (Bona 1999). Não foi verificado se ocorre redução desses carboidratos ao longo das estações do ano ou durante o dia. Novas pesquisas seriam necessárias para fornecer dados a esse respeito. Todavia, é curiosa a variação que ocorre entre as duas espécies estudadas. Acreditamos que esse comportamento está relacionado ao período em que a planta ficou alagada.

A estrutura morfológica e anatômica, das raízes de Bacopa salzmanii e $B$. monnierioides mostra claramente que essas são espécies anfíbias que se adaptam com facilidade, tanto ao ambiente aquático, quanto ao terrestre. Todavia, restam muitas dúvidas quanto à funcionalidade das mesmas, o que só poderia ser esclarecido através de estudos fisiológicos.

\section{Agradecimentos}

Ao professor Dr. Vinicius Castro Souza, pela identificação das espécies; à professora Dra. Edna Scremin Dias pelo auxílio nas coletas; à professora Dra. Marguerite Quorim, pela tradução do resumo em inglês; à Capes, pela concessão de bolsa de doutorado; ao Departamento de Botânica da UFPR e da USP, pela infraestrutura.

\section{Referências bibliográficas}

Alves de Brito, C. J. F. \& Alquini, Y. 1996. A new method for staining botanical meterial embedded in glycol methacrylate (GMA). Arquivos de Biologia e Tecnologia 39(4): 949-950.

Amaral, J. A. M. 1982. Principais relações entre unidades de pastagens, solos e vegetação. In: Encontro de Engenharia Agronômica de Mato Grosso do Sul. Associação de Engenheiros Agrônomos, Campo Grande.

Agami, M. \& Waisel, Y. 1986. The ecophysiology of roots of submerged vascular plants. Physiologie Végétale 24: 607-624.

Arber, A. 1920. Water plants: a study of aquatic angiosperms. University Press, Cambridge.

Armstrong, J. \& Armstrong, W. 1988. Phagmites australis - A preliminary study of soil-oxidizing sites and internal gas transport pathways. New Phytologist 108: 373-382.

Armstrong, J. E. \& Douglas, A. W. 1989. The ontogenic basis for corolla aestivation in Scrophulariaceae. Bulletin of the Torrey Botanical Club 116(4): 378-389.

Armstrong, W.; Justin, S. H. F. W.; Beckett, P. M. \& Lythe, S. 1991. Root adaptation to soil waterlogging. Aquatic Botany 39: 57-73.

Armstrong, W.; Brändle, R. A. \& Jackson, M. B. 1994. Mechanisms of flood tolerance in plants. Acta Botanica Neerlandica 43: 307- 358.

Barnabas, A. D. 1996. Casparian band-like structures in the root hypodermis of some aquatic angiosperms. Aquatic Botany 55: 217-225. 
Barratt, K. 1916. The origin of endodermis in the stem of Hippuris. Annals of Botany 30: 91-99.

Blom, C. W. P. M. 1990. Adaptation of plants to flooding. Aquatic Botany 38: 1.

Bona, C. 1999. Adaptações morfo-anatômicas dos órgãos vegetativos de Bacopa salzmanii (Benth.) Wettst. ex Edwall e Bacopa monnierioides (Cham.) Robinson (Scrophulariaceae) em ambiente terrestre e aquático. Tese de Doutorado, Instituto de Biociências, Universidade de São Paulo.

Bona, C. \& Morretes, B. L. 1997. Anatomia comparativa do caule de Alternanthera philoxeroides (Mart) Griseb. E A. aquatica (Parodi) Chodat. (Amaranthaceae). Arquivos de Biologia e Tecnologia 40(2): 285-296.

Brändle, R. \& Crawford, R. M. M. 1987. Rhizome anoxia tolerance and habitat specialization in wetland plants. p. 397-410. In: R. M. M. Crawford. Plant life in aquatic and amphibious habitats. Blackwell Scientific Publications, Oxford.

Cadavid-Garcia, E. A. 1984. O clima do Pantanal Matogrossense Corumbá, Circular Técnica n. 14 EMBRAPA/ UEPAE, Corumbá.

Carlomagno, J. 1949. Estudio comparativo, morfológico y micrográfico, de las hojas de Digitalis lanata Ehrh. y Digitalis purpurea L. Revista de la Universidad Nacional de Cordoba 36(1): 327-383.

Charlton, W. A. 1966. The root system of Linaria vulgaris Mill. I. Morphologi and anatomy. Canadian Journal of Botany 44(9): 1111-1116.

Cheadle, V. I. \& Whitford, N. B. 1941. Observations on the phloem in the Monocotyledoneae. I. The occurrence and phylogenetic specialisation in structure of the sieve tubes in the metaphloem. American Journal of Botany 28: 623-627.

Conway, V. M. 1937. Studies in the autecology of Cladium mariscus R. Br. III. The aeration of subterranean parts of the plant. New Phytologist 36: 64-96.

Cormack, R. G. H. 1937. The development of root hairs by Elodea canadensis. New Phytologist 36: $19-25$.

Coult, D. A. 1964. Observations on gas movement in the rhizome of Menyanthes trifoliata L., with comments on the role of the endodermis. Journal of Experimental Botany 15: 205-218.

Cutter, E. G. 1987. Anatomia vegetal. Parte II. Órgãos. Roca, São Paulo.

Dale, H. M. 1951. Carbon dioxide and root hair development in Anacharis (Elodea). Science 114: 438-439.
Dale, H. M. 1957. Developmental studies of Elodea canadensis Michx. I. Morphological development at the shoot apex. Canadian Journal of Botany 35: 13-24.

D’Almeida, J. F. R. 1942. A contribution to the study of the biology and physiological anatomy of Indian marsh and aquatic plants. Journal of the Bombay Natural History Society 43: 92-96.

Drew, M. C. 1987. Mechanisms of acclimation to flooding and oxygen shortage in non-wetland species. p. 321-331. In: R. M. M. Crawford. Plant life in aquatic and amphibious habitats. Blackwell Scientific Publications, Oxford.

Esau, K. 1974. Anatomia das plantas com sementes. Edgard Blücher, São Paulo.

Eschrich, W. 1995. Funktionelle Pflanzenanatomie. Springer, Berlin.

Fahn, A. 1990. Plant anatomy. Ed. 4. Pergamon Press, Oxford.

Feder, N. \& O’Brian, T. P. 1968. Plant microtechnique: some principles and new methods. American Journal of Botany 55(1): 123-142.

Franklin, G. L. 1946. A rapid method of softening wood for microtome sectioning. Australian Journal of Botany 33: 393-408.

Gaynard, T. J. \& Armstrong, W. 1987. Some aspects of internal plant aeration in amphibious habitats. In: p. 303-320. R. M. M. Crawford. Plant life in aquatic and amphibious habitats. Blackwell Scientific Publications, Oxford.

Guttenberg, von, H. 1940. Der primäre Bau der Angiospermenwurzel. In: K. Linsbauer. Handbuch der pflanzenanatomie. Berlin. Gebrüder Borntraeger. v. 8. fasc. 39.

Guttenberg, von, H. 1968. Der primäre Bau der Angiospermenwurzel. In: K. Linsbauer. Handbuch der pflanzenanatomie. Berlin, Gebrüder Borntraeger. 8(5):

Hasman, M. \& Inanç, N. 1957. Investigations on the anatomical structure of certain submerged, floating and amphibious hydrophytes. Istanbbul Univiversitesi Tip Fakultesi Mecmuasi 22: $137-53$.

Harkiss, K. J. 1971. Studies in the Scrophulariaceae: IV. Structure of the aerial parts of Antirrhinum majus L. Planta Medica 20(108): 302-313.

Harkiss, K. J. 1972. Studies in the Scrophulariaceae. VII. Structure of the aerial parts of Antirrhinum orontium L. (Misopates orontium (L.) Raf.). Planta Medica 21 (353): 182-190.

Hostrup, O. \& Wiegleb, G. 1991. Anatomy of leaves of submerged and emergent forms of Littorella uniflora (L.) Ascherson. Aquatic Botany 39: 195-209. 
Hutchinson, G. E. 1975. A treatise on Limnology. Limnological Botany. Wiley. v. 3, New York.

Hulbary, R. I. 1944. The influence of air spaces on the three-dimensional shapes in cells in Elodea stems and a comparison with pith cells in Ailanthus. American Journal of Botany 31: 561-580.

IBGE. 1989. Fundação Instituto Brasileiro de Geografia e Estatística. Geografia do Brasil Região Centro Oeste. v.I, p.65-66. Secretaria de Planejamento e Coordenação da Presidência da República. Rio de Janeiro.

Johansen, D. A. 1940. Plant microtechnique. Mc Graw Hill Book, New York.

John, C. D. 1977. The structure of rice roots grown in aerobic and anaerobic environments. Plant Soil 47: 269-274.

Justin, S. H. F. W. \& Armstrong, W. 1987. The anatomical characteristics of roots and plant response to soil flooding. New Phytologist 106: 465-495.

Kaul, R. B. 1976. Anatomical observations on floating leaves. Aquatic Botany 2: 235-270.

Koncalová, H. 1990. Anatomical adaptations to weterlogging in roots of wetland graminoids: limitation and drawbacks. Aquatic Botany 38: 127-134.

Konings, H. \& Verschuren, G. 1980. Formation of aerenchyma in roots of Zea mays in aerated solutions, and its relation to nutrient supply. Physiol Plantarum 49: 265-270.

Laan, P.; Berrevoets, M. J.; Lythe, S.; Armstrong, W. \& Blom, C. W. P. M. 1989. Root morphology and aerenchyma formation as indicators of flood tolerance in Rumex species. Journal of Ecollogy 77: 693-703.

Mauseth, J. D. 1988. Plant antomy. Benjamin/ Cummings, California.

Michener, D. D. C. 1981. Wood and leaf anatomy of Keckiella (Scrophulariaceae): ecological considerations. Aliso 10(1): 3958.

O’Brian, T. P.; Feder, N. \& McCully, M. E. 1964. Polychromatic staining of plant cell walls by toluidine blue O. Protoplasma 59: 368-373.

Pannier, F. 1960. Phisiological responses of Podostemaceae in their natural habitat. Internationale Revoe der Gesamten Hydrobiologie und Hydrogrgrafie 45: 347-354.

Pearsall, W. H. 1918a. The aquatic and marsh vegetation of Esthwaite Water. Journal of Ecology 6: 53-74.

Pearsall, W. H. 1918b. On the Classification of aquatic plant communities. Journal of Ecology 6: 75-84.
Perumalla, C. J.; Peterson, C. A. \& Enstone, D. E. 1990. A survey of angiosperm species to detect hypodermal casparian bands. I. Roots with a uniseriate hypodermis and epidermis. Botanical Journal of the Linnean Society 103: 93-112.

Peterson, C. A.; Emanuel, M. E. \& Wilson, C. 1982. Identification of a casparian band in the hypodermis of onion and corn roots. Canadian Journal of Botany 60: 1529-1535.

Ponzi, R. \& Pizzolongo, P. 1992. Structure and function of Rhinanthus minor L. trichome hydathode ${ }^{1}$. Phytomorphology 42 (1, 2): 1-6.

Pott, V. J. \& Pott, A. 1997. Checklist das macrófitas aquáticas do Pantanal, Brasil. Acta Botanica Brasilica 11(2): 215-227.

Prasad, S. 1947. Pharmacological studies of Brahmi, stem and leaf characteristics of Herpestis monniera H.B.K. and Hydrocotyl [e] asiatica Linn. Journal of the American Pharma Association Sciences 36(12): 393-401.

Priestley, J. H. \& North, E. E. 1922. Physiological studies in plant anatomy. III. The structure of the endodermis in relation to its function. New Phytologist 21: 111-139.

Rascio, N.; Mariani, P.; Vecchia, F. D.; Zanchin, A.; Pool, A. \& Larcher, W. 1994. Ultrastructural and photosynthetic features of leaves and stems of Elodea canadensis. Journal of Plant Physiology 144(3): 314-323.

Renaudin, S. \& Capdepon, M. 1979. Sur quelques aspects de l'ultrastructure des suçoirs de Tozzia alpina L. (Scrophulariaceae). I. Estude des cellules absorbantes. Bulletin Societe Botanique Française 126(2): 165-178.

Richardson, S. D. 1955. The influence of rooting medium on the structure and development of the root cap in seedlings of Acer saccharinum L. New Phytologist 54: 336-337.

Romberger, J. A. 1963. Meristems, growth and development in woody plants: An analytical review of anatomical, physiological, and morphogenic aspects. Technical Bulletin n. 1293, Beltsville.

Roth, I. 1964. Microtecnica vegetal. Universidade Central da Venezuela, Caracas.

Sculthorpe, C. D. 1967. The biology of aquatic vascular plants. St. Martin's Press, New York.

Shannon, E. L. 1953. The production of root hairs by aquatic plants. American Midland Nativalist 50: 474-479.

Sifton, H. B. 1945. Air-space tissue in plants I. Botanical Review 11: 108-143. 
Sifton, H. B. 1957. Air-space tissue in plants II. Botanical Review 23(5): 303-313.

Smirnoff, N. \& Crawford, R. M. M. 1983. Variation in the structure and response to flooding of root aerenchyma in same wetland plants. Annals of Botany 51: 237-249.

Smith, C. A.; Skvirsky, R. C. \& Hirsch, A. M. 1986. Histochemical evidence for the presence of a suberinlike compound in Rhizobium-induced nodules of the nonlegume Parasponia rigida. Canadian Journal of Botany 64: 1474-1483.

Smits, A. J. M.; Laan, P.; Thier, R. H. \& Van Der Velde, G. 1990. Root aerenchyma, oxigen leakage patterns and alcoholic fermentation ability of the roots of some nymphaeid and isoetid macrophytes in relation to the sediment type of their habitat. Aquatic Botany 38: 3-17.

Solereder, H. 1908. Systematic anatomy of the Dicotyledons. v. II, p.1008. Claredon Press, Oxford.

Søndergaard, M. \& Laegaard, S. 1977. Vesiculararbuscular mycorrhiza in some aquatic vascular plants. Nature 268: 231-233.

Sorrell, B. K. 1991. Transient pressure gradient in the lacunar system of the submerged Egeria densa Planch. Aquatic Botany 39: 99-108.

Sorrell, B. K. \& Dromgoole, F. I. 1988. Oxygen transport in the submerged freshwater macrophyte Egeria densa Planch. II Role of lacunar gas pressures. Aquatic Botany 31: 93-106.

Sorrell, B. K. \& Dromgoole, F. I. 1989. Oxygen diffusion and dark respiration in aquatic macrophytes. Plant Cell and Environment 12: 293-299.
Steinmann, F. \& Brändle, R. 1984. Carboydrate and protein metabolism in the rhizomes of the bulrish (Schoenoplectus lacustris L. Palla) in relation to natural development of the whole plants. Aquatic Botany 19: 53-63.

Turgeon, R.; Beebe, D. U. \& Gowan, E. 1993. The intermediary cell: Minor vein anatomy and raffinose oligosaccharide synthesis in the Scrophulariaceae. Planta 191: 446-456.

Van Fleet, D. S. 1950. A comparison of histochemical characteristics of the hypodermis with the endodermis in vascular plants. American Journal of Botany 37: 721-725.

Van Fleet, D. S. 1961. Histochemistry and function of the endodermis. Botanical Review 27: 165-219.

Varghese, T. M. 1970. Studies in the family Scrophulariaceae. II. Floral anatomy of some members of the thibes Verbasceae, Antirrhineae and Cheloneae. Proceedings of the Indian Academy Sciences, Section B 73(2): 65-73.

Varghese, T. M. 1971. Studies in the family Scrophulariaceae: III. Floral anatomy of some members of Gratioleae. Proceedings of the Indian Academy Sciences, Section B 74(1): 6-15.

Williams, B. C. 1947. The structure of the meristematic root tip and origin of the primary tessues in the roots of vascular plants. American Journal of Botany 34: 455-462.

Williams, W. T. \& Barber, D. A. 1961. The fuctional significance of aerenchyma in plants. Symposia of the Society for Experimental Biology 15: 132-144. 